\title{
Geographic variation of elytral color in the sweet potato weevil, Cylas formicarius (Fabricius) (Coleoptera: Brentidae), in Japan
}

\author{
Kiyohisa Kawamura, ${ }^{1,2, *}$ Suguru OHno, ${ }^{1,3}$ Dai Haraguchi, ${ }^{1}$ \\ Shunji KaWASHIMA ${ }^{4}$ and Tsuguo KoHaMA ${ }^{1,3}$ \\ ${ }^{1}$ Okinawa Prefectural Plant Protection Center; Naha, Okinawa 902-0072, Japan \\ ${ }^{2}$ Ryukyu Sankei Co., Ltd.; Naha, Okinawa 902-0072, Japan \\ ${ }^{3}$ Okinawa Prefectural Agricultural Research Center; Itoman, Okinawa 901-0336, Japan \\ ${ }^{4}$ Agriculture, Forestry and Fisheries Department, Oshima Branch of Kagoshima Prefectural Government; Amami, Kagoshima \\ 894-0061, Japan
}

(Received 7 December 2008; Accepted 25 May 2009)

\begin{abstract}
To use elytral color morphs of Cylas formicarius as a genetic marker in its eradication using the sterile insect technique, the geographic distribution of the morphs was examined in the three main infested areas of Japan (Central Ryukyus, Southern Ryukyus, and Ogasawara Islands). In addition to the two known color morphs in Japan (bluish elytra (BE) and greenish elytra (GE)), the piceous elytra (PE) was found mainly in the Southern Ryukyus at low frequency. The color morph frequencies varied between the Central and Southern Ryukyus and between locations within the two areas, while only BE was found in the Ogasawara Islands. PE would be useful for genetically marking sterile weevils to be released. Similarly, GE would be useful in some islands where GE is rarely or not found. BE frequencies on two islands in the Central Ryukyus (Amami and Okinawa) and two islands in the Southern Ryukyus (Miyako and Ishigaki) in 2006-2007 were higher than in 2002-2003.
\end{abstract}

Key words: Eradication program; genetic marking; quarantine pest; Ryukyus; sterile insect technique

\section{INTRODUCTION}

The sweet potato weevil, Cylas formicarius (Fabricius) (Coleoptera: Brentidae), is a serious pest of sweet potato, Ipomoea batatas (L.) Lam. (Convolvulaceae), in tropical and subtropical areas (Sugimoto, 1990; International Institute of Entomology 1993; Setokuchi et al., 1996; AlonsoZarazaga, 2004). It is thought to have originated from India and to have been dispersed on a regional scale mainly by human transportation of infested sweet potato (Wolfe, 1991) because of its limited dispersal ability (Moriya, 1995; Moriya and Hiroyoshi, 1998). In Japan, this weevil was first recorded on Okinawa Island in 1903 (Nawa, 1903) and is currently distributed throughout the Southwest Islands and Ogasawara Islands. Owing to the serious damage caused to sweet potato by this weevil, Japanese plant quarantine regulations have prohibited the transport of host plants from infested areas to other areas in Japan since 1950. To solve this problem, the Kagoshima and Okinawa prefectural governments initiated the $C$. formicarius eradication project using a sterile insect technique (SIT) with the support of the Japanese government (Ohmura, 2000). Sterilized weevils are currently marked with a fluorescent powder dye to distinguish them from wild weevils when they are recaptured by monitoring traps in the field (Kuba et al., 2003); however, it is necessary to develop a better marking technique because the marker can be removed (Kuba et al., 2003).

In insect marking methods, visible genetic variations, such as body and eye color, have often been used as genetic markers to identify insects (reviewed by Hagler and Jackson, 2001), for example, the ebony body coloration of the boll weevil, $A n$ thonomus grandis, was used to study its dispersal

* To whom correspondence should be addressed at: E-mail: kk47923@hotmail.com DOI: 10.1303/aez.2009.505 
and mating behavior (Bartlett, 1967; Bartlett et al., 1968). C. formicarius shows three elytral color polymorphisms: bluish elytra $(\mathrm{BE})$, greenish elytra (GE), and piceous or piceous-brown elytra (PE) (Pierce, 1918, 1940; Kissinger, 1968; Wolfe, 1991). PE, BE, and GE C. formicarius were recorded in India, USA and the Caribbean; and Indonesia and the Philippines, respectively (Pierce, 1918, 1940; Kissinger, 1968; Wolfe 1991); however, their detailed geographic distribution and color morph frequencies have not yet been examined. The BE morph of C. formicarius in Japan was described by Sutherland (1986) and later by Kawamura et al. (2005), who reported the co-occurrence of BE and GE weevils on four islands in the Southwest Islands (Amami Island, Okinawa Island, Miyako Island, and Ishigaki Island) with geographic variation in their frequency. They observed the genetic dominance of GE over BE regardless of sex, but the inheritance pattern of the color morphs was not determined.

To use elytral color morphs of $C$. formicarius as genetic markers, it is necessary to further understand BE and GE geographic distribution, including the exploration of additional color morphs. In the present study, we examined the color morphs of C. formicarius collected in 29 locations that almost covered its distribution range within Japan.

\section{MATERIALS AND METHODS}

C. formicarius were collected using pheromone lures (Lure-II, Sankei Chem. Co., Japan) in the Central and Southern Ryukyus, which are in the Southwest Islands, and in the Ogasawara Islands:
13 locations from the Central Ryukyus in 2006-2007, 12 from the Southern Ryukyus in 2006-2007, and four from the Ogasawara Islands in 2004 and 2007 (Fig. 1; Appendix). Since the color morph frequencies of this weevil did not vary between sexes in the previous study (Kawamura et al., 2005), only males were used in the present study. The collected weevils were preserved in 99.5\% ethanol, air-dried on Kimwipes (Crecia Co., Japan), and classified into color morphs by eye (Fig. 2). When weevils were collected in two or more locations on a single island, we referred to them as different populations based on their distance because of their poor dispersal ability; their maximum flying ability is about $2 \mathrm{~km}$ (Moriya, 1995; Miyatake et al., 1997; Moriya and Hiroyoshi, 1998). The statistical analyses were the Yates chisquare test for color morph frequencies in different periods and locations within single islands and among populations within the main island group, and the Tukey-Kramer test for color morph frequencies among the main island group. To examine

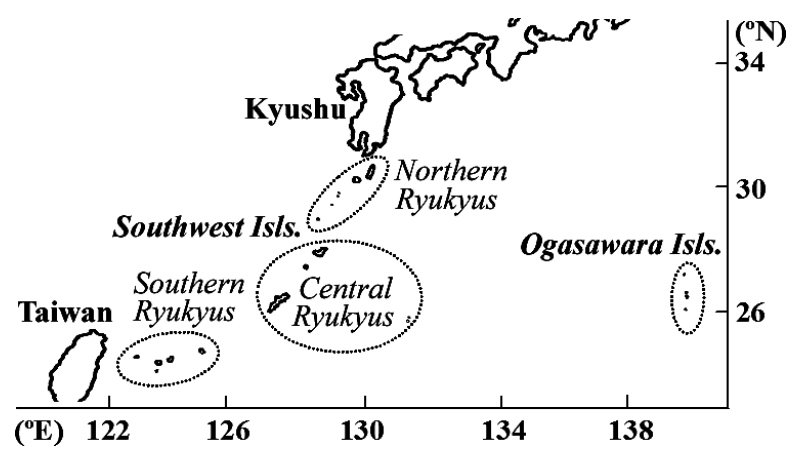

Fig. 1. Locations where C. formicarius males were collected in this study.

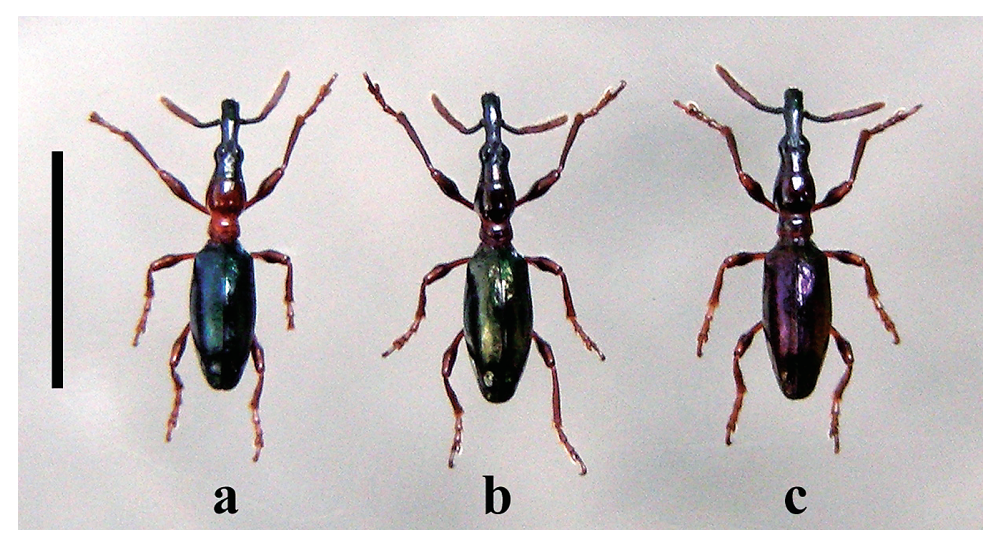

Fig. 2. Elytral color polymorphism in C. formicarius. A. Bluish elytra (BE). B. Greenish elytra (GE). C. Piceous elytra (PE). Scale bar: $5.0 \mathrm{~mm}$. 
Table 1. Within-island comparisons of different periods and locations with regard to color morph frequencies ${ }^{\mathrm{a}}$

\begin{tabular}{|c|c|c|c|}
\hline Tested group & df & $\chi^{2}$ & $p$ \\
\hline \multicolumn{4}{|l|}{ Comparsion among periods } \\
\hline Yomitan Village (Okinawa Island) & 6 & 4.590 & 0.597 \\
\hline Uruma City (Okinawa Island) & 6 & 4.962 & 0.548 \\
\hline Iheya Island & 2 & 5.062 & 0.790 \\
\hline Miyako Island & 6 & 10.769 & 0.095 \\
\hline Ishigaki Island & 6 & 8.365 & 0.212 \\
\hline Funauki (Iriomote Island) & 2 & 0.240 & 0.886 \\
\hline Taketomi Island & 2 & 5.429 & 0.066 \\
\hline Kohama Island & 4 & 5.720 & 0.221 \\
\hline Kuro Island & 2 & 2.966 & 0.226 \\
\hline Hateruma Island & 2 & 0.176 & 0.915 \\
\hline Yonaguni Island & 4 & 2.213 & 0.696 \\
\hline \multicolumn{4}{|l|}{ Comparsion among locations } \\
\hline Amagi Town vs. Isen Town (Tokunoshima Island) & 2 & 0.728 & 0.694 \\
\hline Nago City vs. Yomitan Village vs. Uruma City (Okinawa Island) & 4 & 0.567 & 0.966 \\
\hline Toyohara vs. Funauki (Iriomote Island) & 2 & 48.825 & $<0.001$ \\
\hline
\end{tabular}

${ }^{\text {a }}$ Detailed sampling data are shown in Appendix.

temporal changes in color morph frequencies, the frequencies on Amami Island, Okinawa Island, Miyako Island, and Ishigaki Island, were also compared to those in 2002-2003 (Kawamura et al., 2005) using the Yates chi-square test.

\section{RESULTS}

C. formicarius of non-BE/GE morphs were found on the following nine islands: Kouri Island (Central Ryukyus) and Tarama Island, Ishigaki Island, Iriomote Island, Taketomi Island, Kohama Island, Kuro Island, Hateruma Island, and Yonaguni Island (Southern Ryukyus) (Fig. 2c). These beetles were characterized by a piceous or reddish purple elytra. We referred to this color morph as piceous elytra (PE) according to the description by Pierce (1918, 1940) and Kissinger (1968).

Color morph frequencies did not change during 2006-2007 in the eleven populations examined (Yates chi-square test, $p>0.05$ ) (Table 1; Appendix); hence, the data for these periods were pooled. There was no significant difference in color morph frequencies within islands between two populations on Tokunoshima Island (Amagi Town and Isen Town) and among three populations on Okinawa Island (Nago City, Yomitan Village, and Uruma City) (Yates chi-square test, $p>0.05$ ), while there was a significant difference between two populations on Iriomote Island (Toyohara and Funauki) (same test, $p<0.001$ ) (Table 1; Appendix). Figure 3 shows the geographic distribution of the three color morphs of $C$. formicarius in the Southwest Islands and the Ogasawara Islands of Japan. In the Southwest Islands, BE accounted for $80.2-98.9 \%$ in the Central Ryukyus, but for $15.0-83.8 \%$ in the Southern Ryukyus. PE was mainly found in locations where BE frequencies were $50-60 \%$ and accounted for only $0.1-1.1 \%$. In contrast, BE accounted for $100 \%$ in four of the Ogasawara Islands. There were significant differences in BE frequencies among the Central Ryukyus, the Southern Ryukyus, and Ogasawara Islands (Tukey-Kramer test, $p<0.05$ ) (Table 2). The difference in color morph frequencies was also significant within the Central and Southern Ryukyus (Yates chi-square test, $p<0.001$ ) (Table 2). BE frequencies of Amami Island, Okinawa Island, Miyako Island, and Ishigaki Island in 2006-2007 were significantly higher than in 2002-2003 (Kawamura et al., 2005) (Yates chisquare test, $p<0.05$ ) (Table 3 ).

\section{DISCUSSION}

In the present study, C. formicarius showing PE were found at a low frequency ( $1 \%$ or less). $\mathrm{PE}$ is probably genetically determined because both BE and GE have a genetic basis (Kawamura et al., 2005). In fact, we have recently established a PEmonomorphic population from weevils collected in 


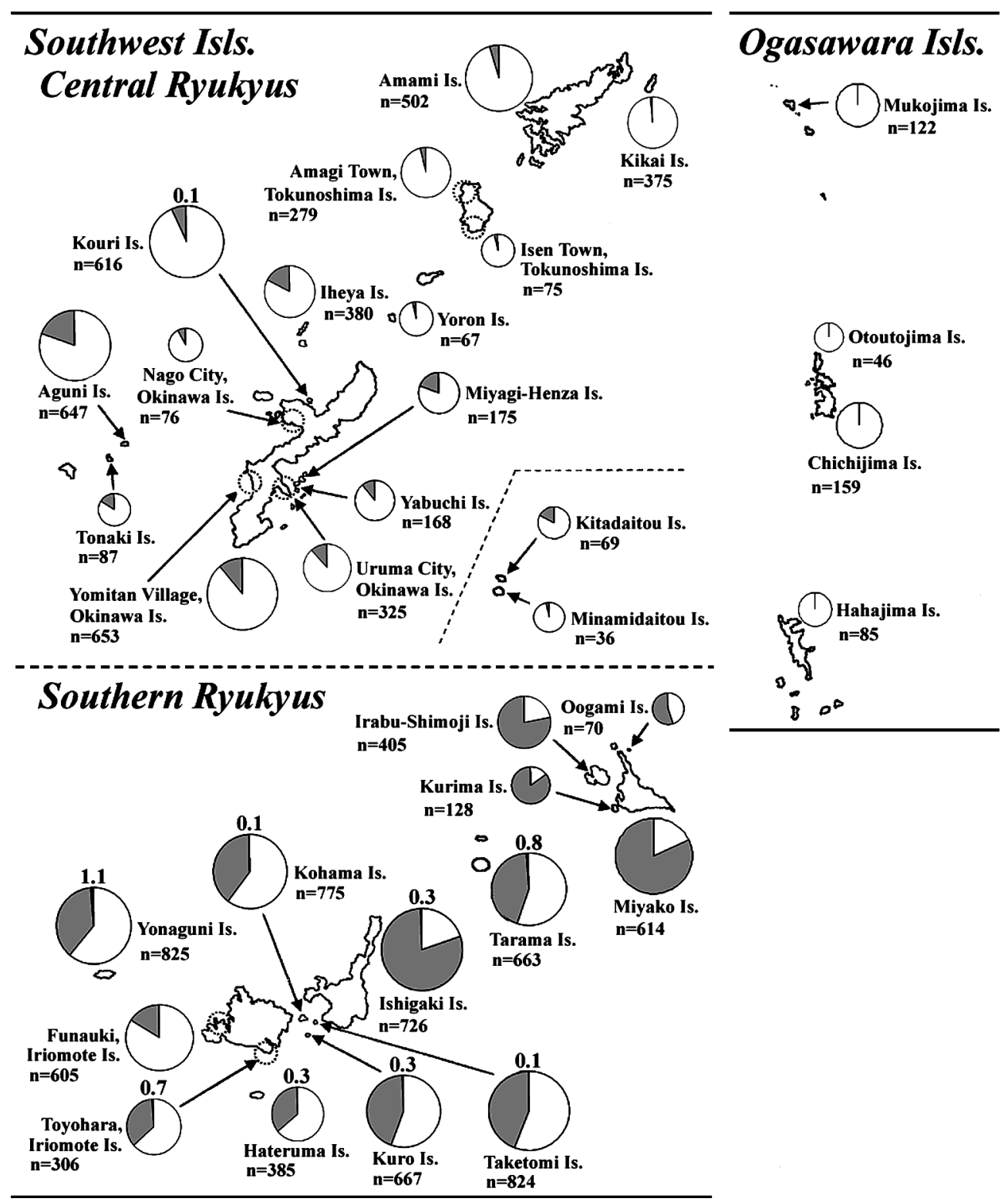

Fig. 3. Geographic distribution of elytral color morphs of C. formicarius in Japan. White represents BE frequency; grey: GE frequency; and black: PE frequency. Numbers near pies represent PE frequencies (in \%). Isls.: Islands; Is.: Island.

Table 2. Comparsions of BE frequencies among and within island groups ${ }^{\mathrm{a}}$

\begin{tabular}{|c|c|c|c|c|c|}
\hline \multirow{2}{*}{ Locality } & \multicolumn{2}{|c|}{ Among island groups } & \multicolumn{3}{|c|}{ Among localities within an island group ${ }^{c}$} \\
\hline & $\begin{array}{c}\text { No. of collection } \\
\text { sites }\end{array}$ & $\begin{array}{l}\text { BE frequency } \\
(\mathrm{Mean} \pm \mathrm{SD})^{\mathrm{b}}\end{array}$ & df & $\chi^{2}$ & $p$ \\
\hline Ogasawara Islands & 4 & $100 \pm 0.0 \mathrm{a}$ & - & - & - \\
\hline Central Ryukyus & 16 & $90.0 \pm 6.4 \mathrm{~b}$ & 30 & 276.518 & $<0.001$ \\
\hline Southern Ryukyus & 13 & $47.3 \pm 21.7 \mathrm{c}$ & 24 & 1101.921 & $<0.001$ \\
\hline
\end{tabular}

${ }^{a}$ Detailed sampling data are shown in Appendix.

${ }^{\mathrm{b}}$ Numbers followed by different letters are significantly different at the $5 \%$ level (Tukey-Kramer test on arcsine-transformed data).

'Yates' chi-square test. 
Table 3. Comparisons of color morph frequencies from four islands between 2002-2003 and 2006-2007

\begin{tabular}{|c|c|c|c|c|c|c|c|c|}
\hline \multirow{2}{*}{ Island } & \multirow{2}{*}{$\begin{array}{l}\text { Collection } \\
\text { year }\end{array}$} & \multirow{2}{*}{$\begin{array}{c}\text { No. of } \\
\text { weevils } \\
\text { examined }\end{array}$} & \multicolumn{3}{|c|}{ No. (\%) of weevils ${ }^{b}$} & \multirow{2}{*}{$\mathrm{df}$} & \multirow{2}{*}{$\chi^{2}$} & \multirow{2}{*}{$p$} \\
\hline & & & $\mathrm{BE}$ & GE & $\mathrm{PE}$ & & & \\
\hline \multirow[t]{2}{*}{ Amami Island } & $2002-2003^{a}$ & 208 & $188(90.4)$ & $20(9.6)$ & $0(0)$ & \multirow{2}{*}{2} & \multirow{2}{*}{6.326} & \multirow{2}{*}{0.042} \\
\hline & 2007 & 502 & $480(95.6)$ & $22(4.4)$ & $0(0)$ & & & \\
\hline \multirow{2}{*}{ Okinawa Island } & $2002-2003^{a}$ & 176 & $122(69.3)$ & $54(30.7)$ & $0(0)$ & \multirow{2}{*}{2} & \multirow{2}{*}{48.086} & \multirow{2}{*}{$<0.001$} \\
\hline & 2006-2007 & 1,054 & $939(89.1)$ & $115(10.9)$ & $0(0)$ & & & \\
\hline \multirow{2}{*}{ Miyako Island } & $2002-2003^{a}$ & 236 & $9(3.8)$ & $227(96.2)$ & $0(0)$ & \multirow{2}{*}{2} & \multirow{2}{*}{26.551} & \multirow{2}{*}{$<0.001$} \\
\hline & 2006-2007 & 614 & $109(17.8)$ & $505(82.2)$ & $0(0)$ & & & \\
\hline \multirow[t]{2}{*}{ Ishigaki Island } & $2002-2003^{\mathrm{a}}$ & 250 & $5(2.0)$ & $245(98.0)$ & $0(0)$ & \multirow[b]{2}{*}{2} & \multirow{2}{*}{45.499} & \multirow{2}{*}{$<0.001$} \\
\hline & 2006-2007 & 726 & $146(20.1)$ & $578(79.6)$ & $2(0.3)$ & & & \\
\hline
\end{tabular}

${ }^{\text {a }}$ Refers to the results of Kawamura et al. (2005).

${ }^{\mathrm{b}} \mathrm{BE}, \mathrm{GE}$, and PE: Weevils showing bluish elytra, greenish elytra, and piceous elytra, respectively.

Yonaguni Island (Kawamura et al., unpublished), strongly supporting the genetic basis of PE. Therefore, PE would be useful for genetically marking sterile weevils to be released in the $C$. formicarius eradication project using SIT in Kagoshima and Okinawa Prefecture (Southwest Islands) or in other areas (Ogasawara Islands) if the eradication project is extended in the future. Similarly, GE would be useful in some locations where GE is rare (e.g., Kikai Island and Minamidaitou Island) or does not exist (e.g., Ogasawara Islands).

Because the quality of mass-reared insects affects the efficacy of a SIT program (Huettel, 1976), the ecological and physiological characteristics (e.g., sexual competitiveness, dispersal ability, and longevity) have been examined using mass-reared insects to be released as sterilized insects (e.g., Nakamori and Soemori, 1981; Koyama et al., 2004; Matsuyama and Kuba, 2004; Kumano et al., 2007). To successfully introduce $C$. formicarius showing PE as a genetic marker in SIT, it is important to compare these characteristics between PE weevils and other colored weevils, and to clarify the inheritance pattern of the three color morphs.

In contrast to the Central and Southern Ryukyus (Southwest Islands), only BE existed in the Ogasawara Islands. In addition, color morph frequencies varied both between the Central and Southern Ryukyus and between locations within the same areas. A possible factor influencing monomorphism in the Ogasawara Islands is the difference in its invasion source. Kawamura et al. (2007) suggested that the sources of populations of the Ogasawara Islands differed from those of the South- west Islands based upon differences in the nucleotide sequences of the internal transcribed spacer-1 region. C. formicarius in the Ogasawara Islands may have originated from a monomorphic population of elytral color or from a small number of BE weevils in a polymorphic population.

The present study also revealed that BE frequencies increased from 2002-2003 to 2006-2007 in all four islands examined, although it is uncertain why they increased. We need to continue research to clarify temporal changes in color morph frequencies of the respective islands to introduce elytral color morphs of $C$. formicarius as genetic markers in SIT.

\section{ACKNOWLEDGMENTS}

We are grateful to the following people for their help in supplying $C$. formicarius males: Drs M. Yamagishi and N. Kumano, Ms T. Ganaha and Y. Tamura, and Messrs M. Hokama, N. Kirihara, S. Ito, S. Sato, S. Taniyama, T. Hiramoto, T. Shibata, T. Ohishi, T. Uesato, and Y. Ohshiro. We also wish to thank Messrs S. Sukenari, T. Yokoyama, Y. Aoki, and Y. Shinzato for their kind help.

\section{REFERENCES}

Alonso-Zarazaga, M. A. (2004) Cyladinae Schoenherr, 1823 (Coleoptera, Curculionoidea). In Brentidae of the World (Coleoptera, Curculionoidea) (A. Sforzi and L. Bartolozzi, eds.). Museo Regionale di Scienze Naturali, Torino, Italy, pp. 855-871.

Bartlett, A. C. (1967) Genetic markers in the boll weevil. J. Hered. 58: 159-163.

Bartlett, A. C., N. M. Wilson and E. B. Mattix (1968) The fate of genetic markers in populations of boll weevils. $J$. Econ. Entomol. 61: 808-812.

Hagler, J. R. and C. G. Jackson (2001) Methods for marking insects: current techniques and future prospects. Аnnu. 
Rev. Entomol. 46: 511-543.

Huettel, M. D. (1976) Monitoring the quality of laboratory reared insect: a biological and behavioral perspective. Environ. Entomol. 5: 807-814.

International Institute of Entomology (1993) Distribution Maps of Pests: Cylas formicarius (F). Series A (Agricultural), Map No. 278. International Institute of Entomology, London.

Kawamura, K., I. Kandori, Y. Sakuratani and T. Sugimoto (2005) On elytral dimorphism of sweet potato weevil, Cylas formicarius (Fabricius), in the Southwest islands, Japan. Mem. Fac. Agr. Kinki Univ. 38: 1-7.

Kawamura, K., T. Sugimoto, K. Kakutani, Y. Matsuda and H. Toyoda (2007) Genetic variation of sweet potato weevils, Cylas formicarius (Fabricius) (Coleoptera: Brentidae), in main infested areas in the world based upon the internal transcribed spacer-1 (ITS-1) region. Appl. Entomol. Zool. 42: 89-96.

Kissinger, D. G. (1968) Curculionidae Subfamily Apioninae of North and Central America. With Reviews of the World Genera of Apioninae and World Genera of Apion Herbst (Coleoptera). Taxonomic Publications, South Lancaster, Massachusetts. vii +559 pp.

Koyama, J., H. Kakinohana and T. Miyatake (2004) Eradication of the melon fly Bactrocera cucurbitae in Japan: importance of behavior, ecology, genetics, and evolution. Annu. Rev. Entomol. 49: 331-349.

Kuba, H., T. Kohama and D. Haraguchi (2003) Eradication projects of exotic sweet potato weevils using SIT in Okinawa. In Proceedings of the NIAES-FFTC Joint International Seminar on Biological Invasions: Environmental Impacts and the Development of a Database for the Asian-Pacific Region (M. Oka, M. Matsui, T. Shiomi, Y. Ogawa and K. Tsuchiya, eds.). National Institute for Agro-Environmental Sciences, Tsukuba, and Food and Fertilizer Technology Center for the Asian and Pacific Region, Taipei, pp. 273-287.

Kumano, N., T. Kohama and S. Ohno (2007) Effect of irradiation on dispersal ability of male sweetpotato weevils (Coleoptera: Brentidae) in the field. J. Econ. Entomol. 100: 730-736.

Matsuyama, T. and H. Kuba (2004) Can the Okinawa massreared strain of the melon fly, Bactrocera cucurbitae Coquillett (Diptera: Tephritidae) mate with the Taiwan wild strain? Appl. Entomol. Zool. 39: 279-282.
Miyatake, T., S. Moriya, T. Kohama and Y. Shimoji (1997) Dispersal potential of male sweetpotato weevils (Coleoptera: Brentidae) over land and water. Environ. Entomol. 26: 272-276.

Moriya, S. (1995) A preliminary study on the flight ability of the sweet potato weevil, Cylas formicarius (Fabricius) (Coleoptera: Apionidae) using a flight mill. Appl. Entomol. Zool. 30: 244-246.

Moriya, S. and S. Hiroyoshi (1998) Flight and locomotion activity of the sweet potato weevil (Coleoptera: Brentidae) in relation to adult age, mating status, and starvation. J. Econ. Entomol. 91: 439-443.

Nakamori, H. and H. Soemori (1981) Comparison of dispersal ability and longevity for wild and mass-reared melon flies, Dacus cucurbitae Coquillett (Diptera: Tephritidae) under field conditions. Appl. Entomol. Zool. 16: 321327.

Nawa, U. (1903) On the sweet potato weevil. Kontyu Sekai 7: 327-330 (in Japanese).

Ohmura, K. (2000) The significance of eradication of sweet potato weevil and small sweetpotato weevil, and the development of eradication project for these weevils. Plant Prot. 54: 1 (in Japanese).

Pierce, W. D. (1918) Weevils which affect Irish potato, sweet potato, and yam. J. Agric. Res. 12: 601-611+7 plates.

Pierce, W. D. (1940) Studies of the sweet potato weevils of the subfamily Cyladinae. Bull. S. Calif. Acad. Sci. 39: 205-223+5 plates.

Setokuchi, O., K. Kawasoe and T. Sugimoto (1996) Invasion of the Sweet potato weevil, Cylas formicarius (Fabricius) into Southern Islands in Japan and strategies for its eradication. In Proceedings of the International Workshop on Pest Management Strategies in Asian Monsoon Agroecosystems (N. Hokyo and G. Norton, eds.). KNAES, Kumamoto, pp. 197-207.

Sugimoto, T. (1990) Biology of sweet potato weevil. Plant Prot. 44: 107-110 (in Japanese).

Sutherland, J. A. (1986) A review of the biology and control of the sweetpotato weevil Cylas formicarius (Fab.). Trop. Pest Manage. 32: 304-315.

Wolfe, G. W. (1991) The origin and dispersal of the pest species of Cylas with a key to the pest species groups of the world. In Sweet Potato Pest Management, A Global Perspective (R. K. Jansson and K. V. Raman, eds.). Westview Press, Boulder, pp. 13-43. 


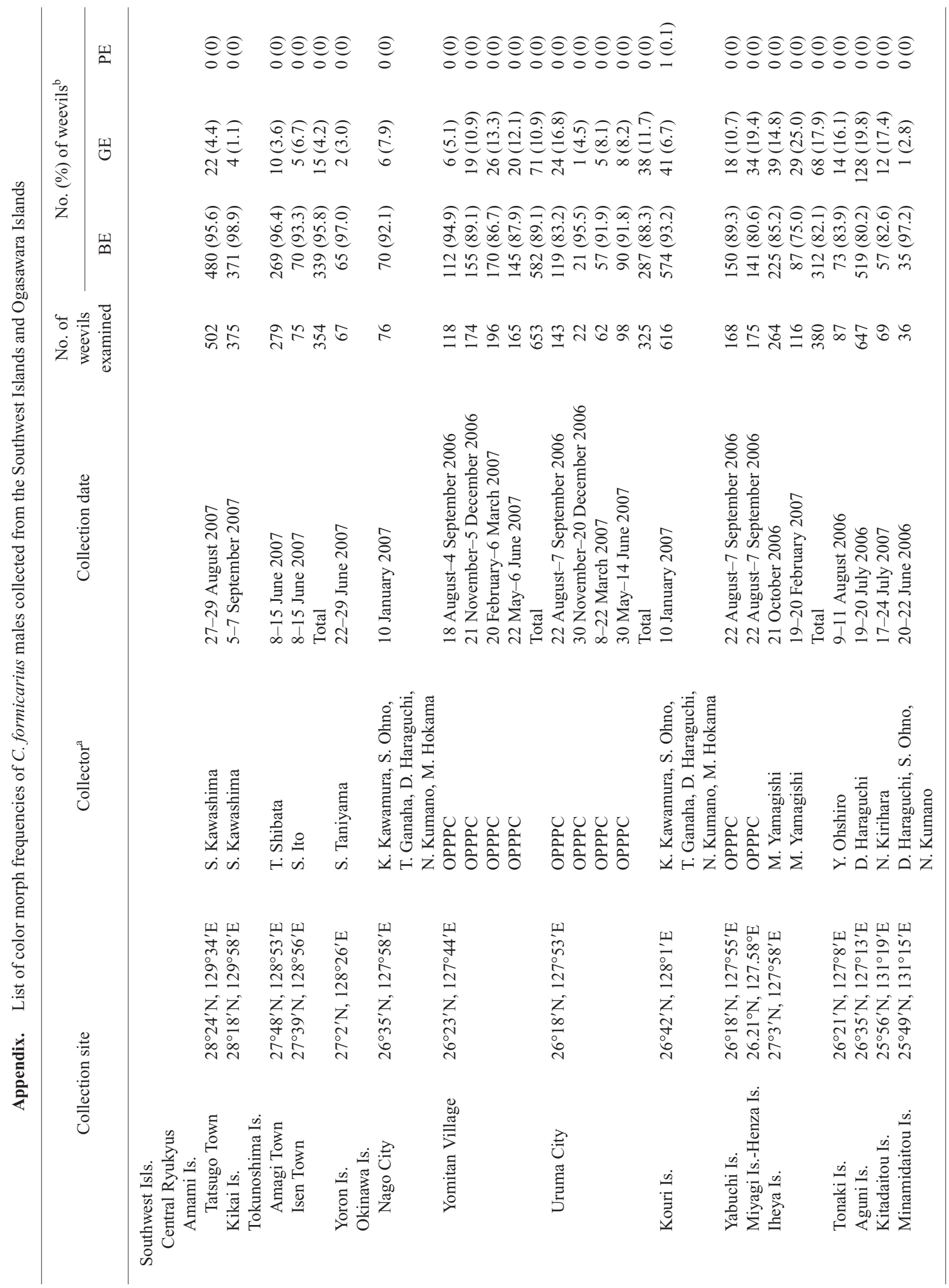




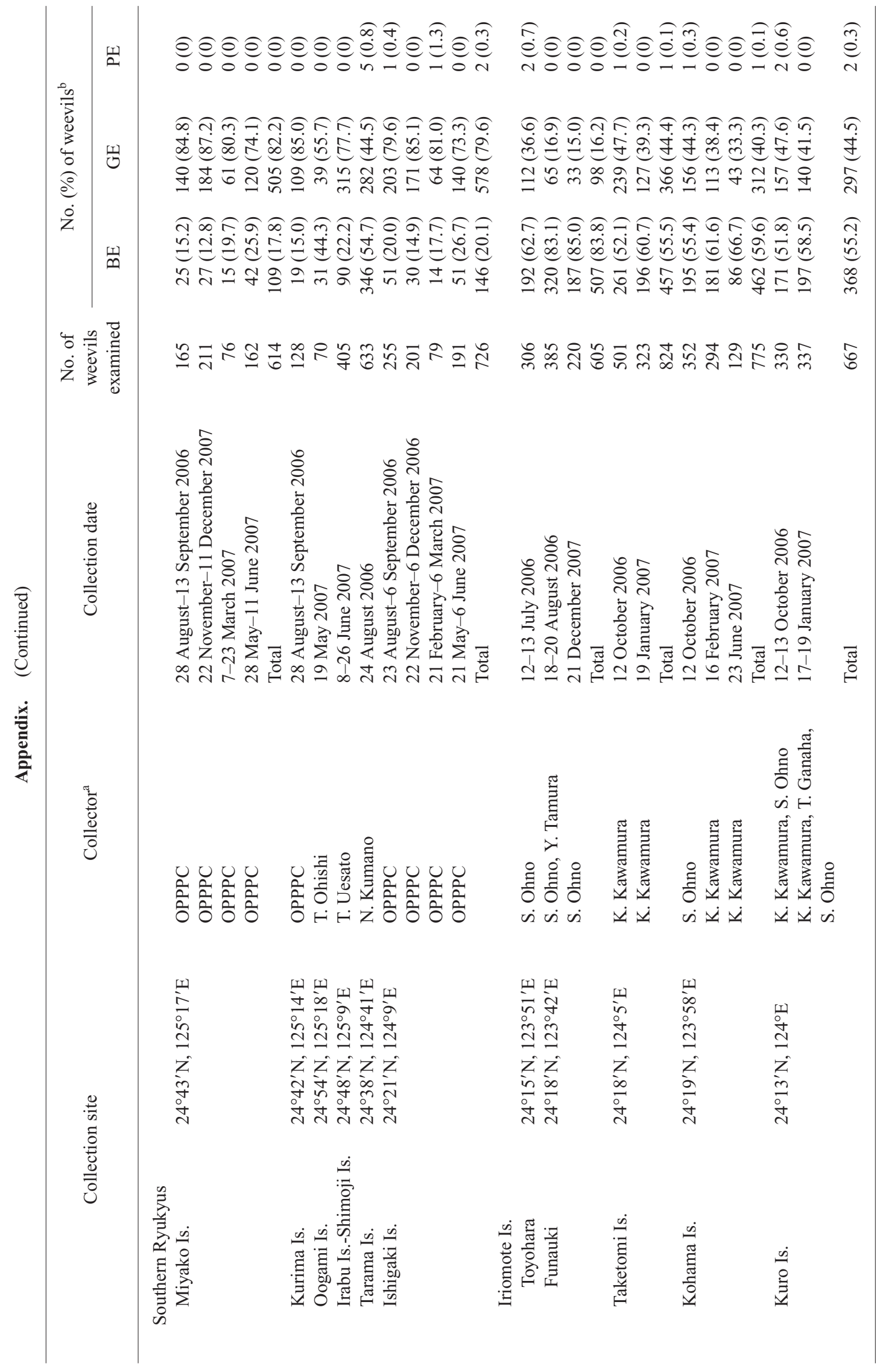




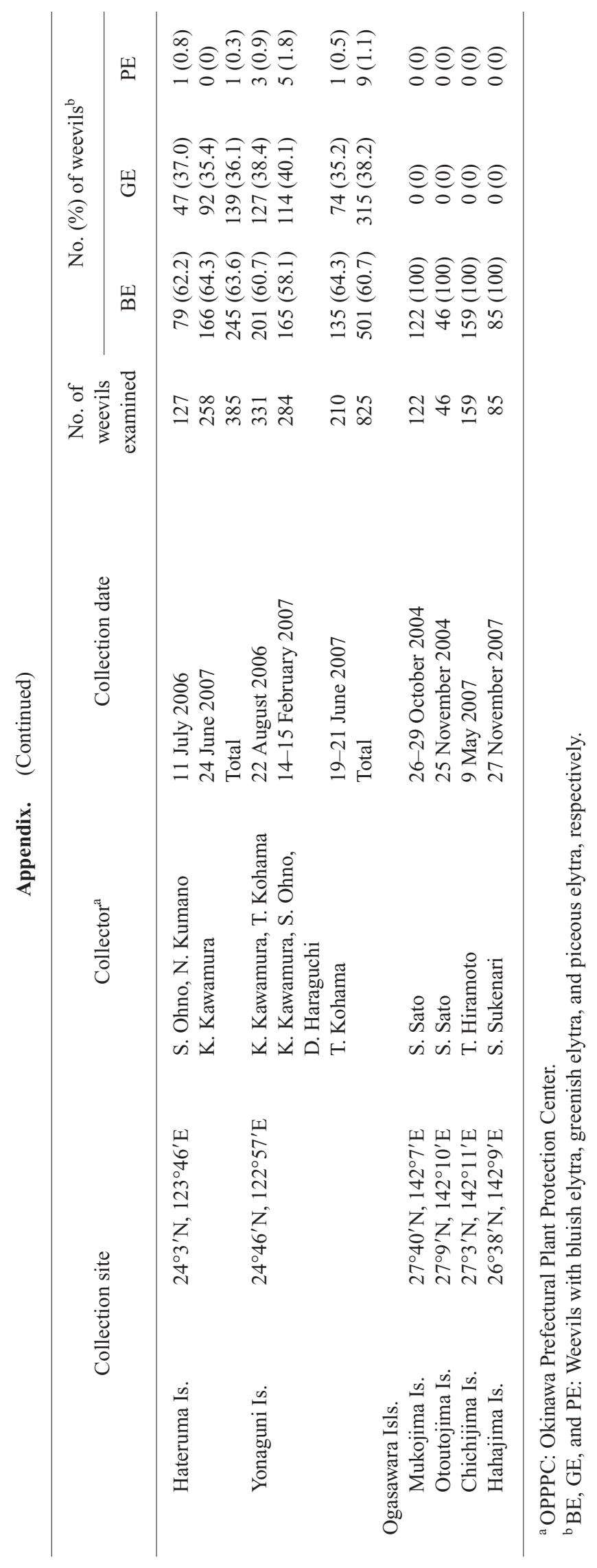

